\title{
Research and Practice of Scientific Research Management Reform Based on Collaborative Innovation
}

\author{
ZHOU Lin ${ }^{1, a}$, XU Jinfu, ${ }^{2, b}$, DAI Jiaoyan ${ }^{2, c}$ and XU Xuebo ${ }^{2, d}$ \\ ${ }^{1}$ School of Mechanical Engineering, Ningbo University of Technology, \\ Ningbo 315016, China \\ ${ }^{2}$ School of Materials Science and Engineering, Ningbo University of Technology, \\ Ningbo 315016, China \\ atopgun_1980@163.com, ${ }^{b} x j f 7413 @$ sina.com, 'daijiaoyan@nbut.net, 'xuxuebo@nbut.net
}

\begin{abstract}
Keywords: Collaborative innovation, Local colleges, Scientific research management, Reform
Abstract. Collaborative innovation which has important significance is the activity of optimizing innovation resources. However, in the process of promoting cooperative innovation, scientific research management of local colleges are facing a lot of challenges, such as how to activating the research resources, how to positioning the government functions correctly and how to promoting scientific achievements transformation. Ningbo University of Technology, as a local colleges, during the process of establishing collaborative innovation centers in different levels, had carried out relevant theoretical research and application analysis, proposed some of the innovation mechanism and methods of scientific research management, and explored a new path for scientific research management reform.
\end{abstract}

\section{Introduction}

During the "11th five-year plan", a major adjustment of science and technology developing policy in China had taken place. The key point of the policy adjustment is to support and encourage enterprises to become the main body of technological innovation. At the same time, the purpose of the policy adjustment is also to eliminate the constrains of cooperation and innovation in scientific research activities and to promote the development of innovation which is precisely the key point of collaborative innovation[1,2].

The concept of collaboration comes from the synergetics theory, which was put forward by Hermann Haken in 1973 at the earliest[3-5]. The notable characteristic of synergy(Collaboration) is that new results and goals that cannot be achieved by a single individual can be achieved by appearing spontaneously orderly structure in time, space and function through the interaction between each individual[6,7]. Collaborative innovation can achieve transition of innovation system or activities from disorderly to orderly. And this transition process based on the self-organizing process, combined with the appropriate management and control[8].

Since the reform and opening-up, reformation and development in Chinese economy was significant. However, reformation in Chinese scientific research management policy was few. This kind of institutional obstacles has become the "bottleneck" of the development of science and technology in china. And it is an effective way to reform the scientific research management policy based on collaborative innovation.

\section{College Scientific Research Management Reform}

Colleges and universities are the main body of scientific and technological innovation in China. In order to ensure effective development of collaborative innovation, the college scientific research management policy needs to be totally innovated.

The college collaborative innovation organization and run chart was shown in Fig.1. It can be seen from the figure that the innovation activities carried out centered around the college, and the government, enterprises and research institutes participated in the collaborative innovation activities[9-11]. In the collaborative innovation activities, knowledge, skills, and scientific research resources were exchanged, with 
that knowledge transformation, technology research and the cultivation of researchers were implemented[12].

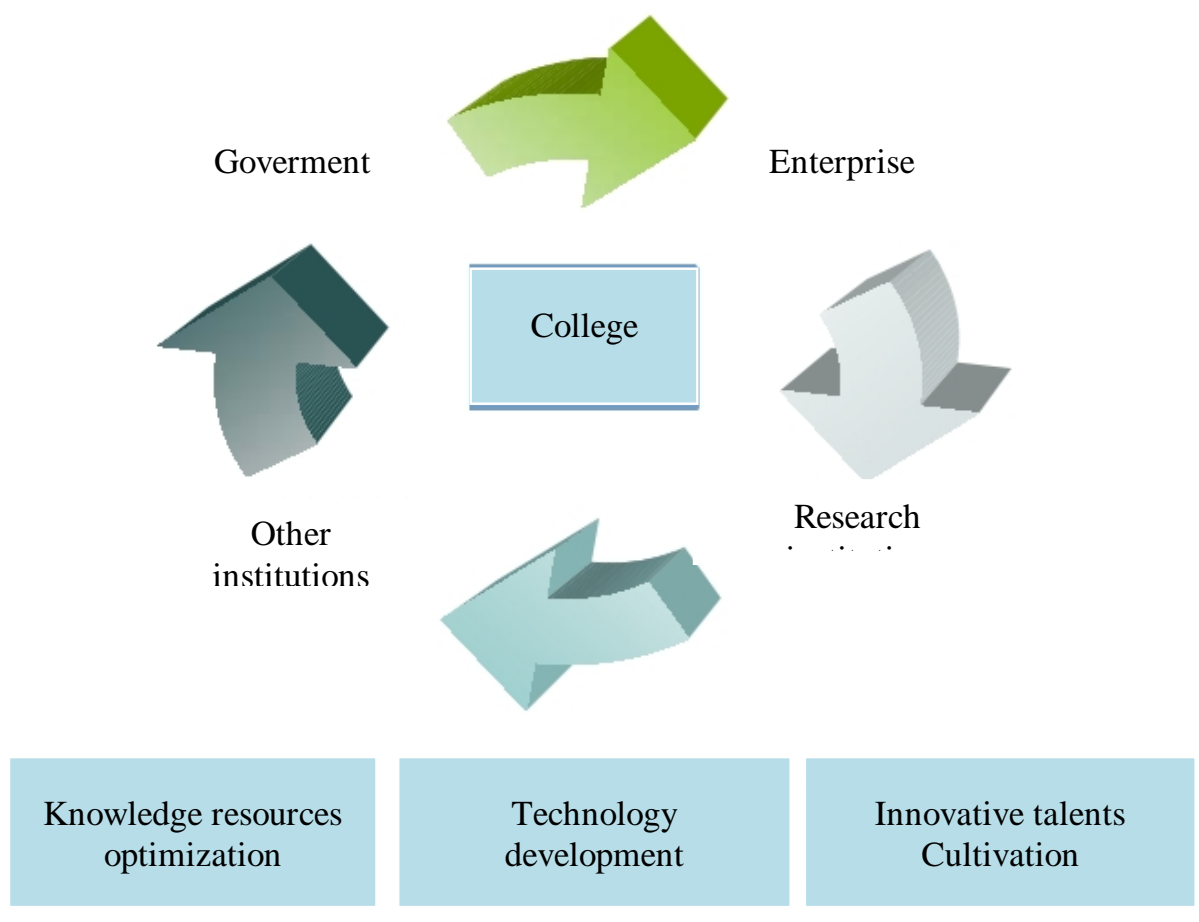

Fig.1 The college collaborative innovation organization and run chart

Benefit sharing between the college collaborative innovation institutions should meet the needs of college and enterprise at the same time[13,14]. In order to avoid interference between organizations caused by internal or external factors, the security and realization mechanism of benefit sharing must be set up, as shown in Fig.2.

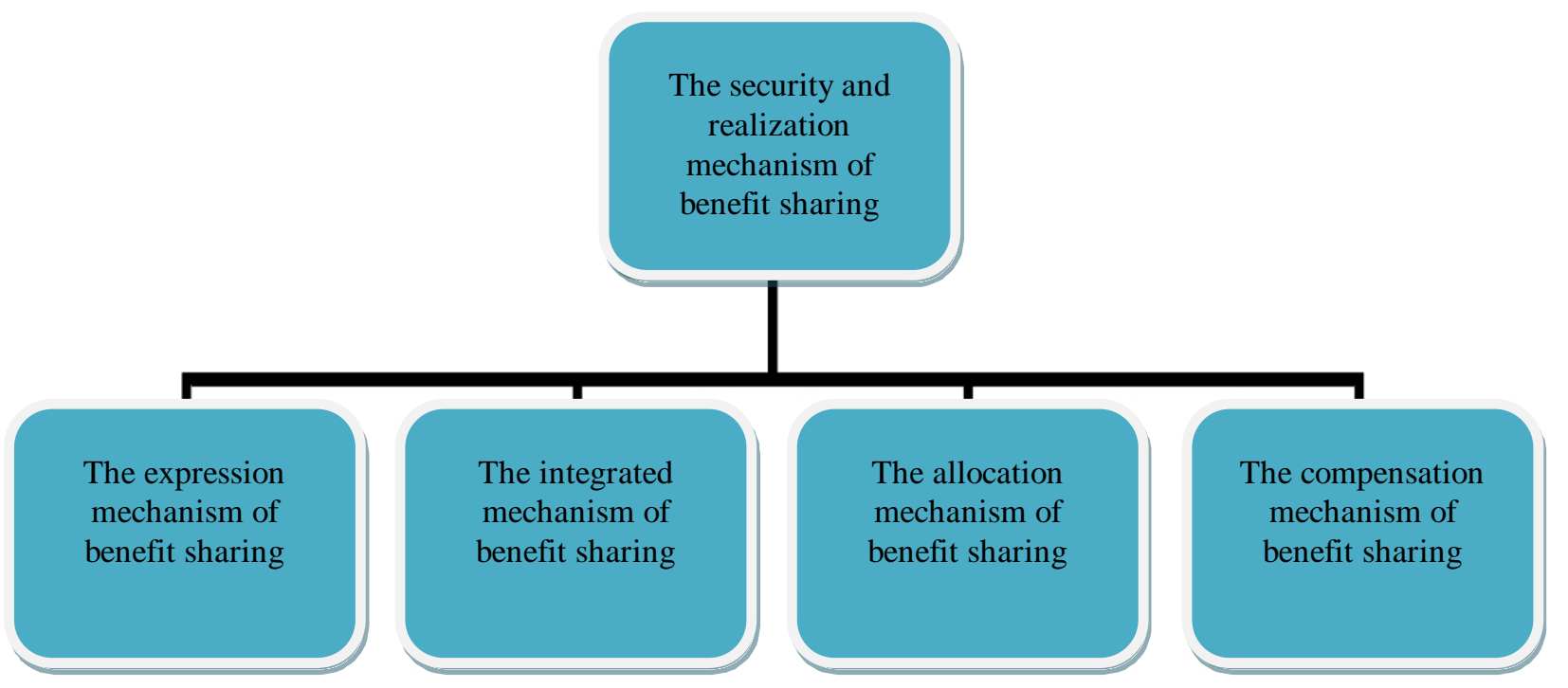

Fig.2 The security and realization mechanism of benefit sharing 


\section{Collaborative Innovation Reform Practice in Local College}

Local college is an important part in the higher education system in China. Local college should be positioning accurately in education and scientific research activities according to its own characteristics and comparative advantages. As a local college on the background of engineering, Ningbo University of Technology always focused on applied research and university-industry cooperation.

Since 2008, the Ningbo University of Technology had set up 5 cooperation platforms to innovate cooperation mode constantly and to create conditions for the university-industry scientific cooperation. Later then, there were 10 on-campus collaborative innovation centers and 1 intelligent traffic collaborative innovation center had been set up to promote the development of the regional collaborative innovation activities. After the reform practice of recent years, some reform measures of scientific research management policy in local college had been summarized as follows:

Optimal Configuration of Scientific Research Resources on-Campus. The Ningbo University of Technology had made more explicit the goal that scientific activities on-campus should be more forced on applied research. Therefore, the scientific research resources on-campus were integrated effectively by combining various laboratory laboratories, research institutes and training bases between different disciplines.

Improvement of the Research Institutions of Collaborative Innovation. Through the construction and improvement of various research institutions of collaborative innovation, the pattern of industry-university-research cooperation was strengthened, and the implementation of long-term research projects was guaranteed. Take advantage of these research institutions, the technical problems from local enterprises can be researched and solved efficiently.

Reform of the Personnel Management System. In order to adapt to the requirement of collaborative innovation, the personnel management system such as the researchers employment, professional title evaluation and performance assessment needs to change significantly. For all kinds of collaborative innovation institutions, The Ningbo University of Technology employed a certain number of full-time researchers, meanwhile encouraged teachers to engage in special research in enterprises or other scientific research institutions by short-term departure. And in recent years, good results had been achieved in the field of industry-university-research cooperation.

Improvement of the Coordination Mechanism of Students Education and Scientific Research. The function of colleges are both students education and scientific research, therefore colleges need to establish a mechanism of integration of scientific research and education in the process of the construction of collaborative innovation centers. The Ningbo University of Technology established an new evaluation system for education and research activities integration in the collaborative innovation reform practice, and set up the goal of cultivating a higher level of applied technology talents.

\section{Conclusions}

Science and technology development needs a scientific and efficient management policy to support. The scientific research management reform based on collaborative innovation is the specific activity for the cultivation and integration of innovation resources. This reform has very important significance for the promotion of the college scientific research level, meanwhile it is the basic guarantee of the college innovation ability improvement and a effective way of innovation elements convergence.

The Ningbo University of Technology as a typical local college, in the basis of in-depth analysis of the current situation and problems of existing scientific research management policy, carried out relevant theoretical research and application analysis in combination with all levels of collaborative innovation center construction practice. The innovation mechanism and methods of scientific research management was put forward and the new path and pattern was found out for the reform of scientific research management, and some policy guidance notes were provided for the implementation of collaborative innovation. 


\section{Acknowledgements}

This work was financially supported by Ningbo Soft Science Foundation (2014A10035).

\section{References}

[1] Y.S. Lee: Research Policy Vol. 25(1996), p. 843

[2] Y.L. Doz, G. Hamel: Alliance Aadvantage: the Art of Creating Value through Partnering (Harvard Business Press, Boston 2010).

[3] V. Senano, T. Fischer: International Manufacturing Vol. 18(2007), p. 599

[4] G. Harman: Higher Education Management and Policy Vol. 17(2005), p. 152

[5] J. Leea, H.N. Win: Technovation Vol. 24(2004), p. 266

[6] N. Brandenburger: Co-opetition (Harvard Business Press, Boston 2010).

[7] Yukio Miyata: Technovation Vol. 20(2000), p. 520

[8] N. Albert, T. John: Research Policy Vol. 34(2005), p. 780

[9] D. Hicks, K. Hamilton: Issues in science and technology Vol. 12(2001), p. 164

[10] M. Kenney: Biotechnology: The University Industrial Complex. (Yale University Press, New Haven 1986).

[11] B. Bozeman: Research Policy Vol. 29(2000), p. 570

[12] G. Harman: Higher Education Management and Policy Vol. 17(2005), p. 345

[13] B.H. Ches, B.W. Vanhaver, and J. Wes: Open Innovation: Researching a New Paradigm (Oxford University Press, Oxford 2006).

[14] H. Duin, J. Jaskov, A. Hesmer, and K.D. Thoben: Towards a Framework Forcoll Abortive Innovation (Springer, Bostin 2008). 